\title{
Foliar application of melatonin induces tolerance to drought stress in Moldavian balm plants (Dracocephalum moldavica) through regulating the antioxidant system
}

\author{
Rozita Kabiri', Ali Hatami' ${ }^{1}$ Hakimeh Oloumi ${ }^{2 *}$, Mehdi Naghizadeh ${ }^{3}$, \\ Fatemeh Nasibi', Zahra Tahmasebi ${ }^{1}$ \\ ${ }^{1}$ Department of Agronomy and Plant Breeding \\ Ilam University, Ilam, Iran \\ ${ }^{2}$ Department of Ecology, Institute of Science and High Technology and Environmental Sciences \\ Graduate University of Advanced Technology, Kerman, Iran \\ ${ }^{3}$ Department of Agronomy and Plant Breeding \\ Shahid Bahonar University of Kerman, Kerman, Iran \\ ${ }^{4}$ Biology Department \\ Shahid Bahonar University of Kerman, Kerman, Iran
}

\begin{abstract}
Melatonin, as an indoleamine molecule, regulates a wide range of physiological functions during the growth, morphogenesis and response of plants to biotic and abiotic stresses. In this research, the effect of exogenous application of melatonin ( 0 (distilled water), 50,100 and $150 \mu \mathrm{M}$ ) to the leaves of Moldavian balm plants grown under different levels of drought stress (100\% (control), $80 \%, 60 \%$ and $40 \%$ of field water capacity) was investigated. The results indicate that plants which were treated with $100 \mu \mathrm{M}$ melatonin showed the greatest leaf surface area, lateral branching, flower length and activities of antioxidant enzymes (superoxide dismutase, guaiacol peroxidase and ascorbate peroxidase). Foliar application of $100 \mu \mathrm{M}$ melatonin had no significant difference in catalase activity in comparison with the control and other concentrations of melatonin under normal, moderate and severe drought stress conditions. The lowest $\mathrm{H}_{2} \mathrm{O}_{2}$ content and lipid peroxidation (electrolyte leakage, concentrations of malondialdehyde and other aldehydes) were obtained at the concentration of $100 \mu \mathrm{M}$ melatonin under severe drought stress. This concentration also significantly increased the chlorophyll content and enhanced the relative water content; however, foliar application of $100 \mu \mathrm{M}$ melatonin had no significant effect on leaf length and proline content compared with the control under normal and stress conditions. The obtained results suggested that foliar application of $100 \mu \mathrm{M}$ melatonin was more effective than the concentrations of 50 and $150 \mu \mathrm{M}$ melatonin in reducing the adverse effects of moderate and severe drought stress.
\end{abstract}

Keywords: antioxidant enzymes, dragonhead, lipid peroxidation, melatonin, oxidative damage

\section{Abbreviations:}

APX - ascorbate peroxidase, CAT - catalase, Chl T - total chlorophyll, EL - electrolyte leakage, GPX - guaiacol peroxidase, MDA - malondialdehyde, ROS - reactive oxygen species, RWC - relative water content, SOD - superoxide dismutase, TBARS - thiobarbituric acid reactive substance

*Corresponding author. 


\section{INTRODUCTION}

Drought stress is one of the most serious and widespread problems which limits plant productivity because it has a negative effect on plant physiology. The effects of drought stress strongly depend on its duration, intensity, and the phonological phase of growth and genetic tolerance capacity of plants that could reduce the growth of plants, so that caused the changes of the morphological and physiological structures and the distribution pattern of biomass or even death (Gamze et al., 2005). Drought stress causes oxidative damage by the accumulation of reactive oxygen species (ROS) that inhibit photosynthesis, stomatal closure and alter the activities of enzymes (Maksup et al., 2014). ROS formation is considered a threat to the cell because it leads to electron leakage, lipid peroxidation and subsequent membrane damage, as well as damage to nucleic acids and proteins (Polle, 2001). To reduce these damages, plants have enhanced enzymatic (including superoxide dismutase (SOD), ascorbate peroxidase (APX), catalase (CAT) and guaiacol peroxidase (GPX)) and non-enzymatic (such as ascorbic acid, glutathione, carotenoids and $\alpha$-tocopherol) defence mechanisms, osmotic adjustment and stomata regulation (Shi et al., 2007). One of the objectives of advanced plant physiology is to distinguish efficient, economic and inexpensive compounds for enhancing plant tolerance to biotic and abiotic stresses. The results achieved in recent years strongly assert that melatonin could be a promising compound for the reduction of environmental stresses, especially water deficit (Arnao and Hernandez-Ruiz, 2014; Arnao and Hernandez-Ruiz, 2015; Nawaz et al., 2016; Shi et al. 2016).

Melatonin (N-acetyl-5-methoxytryptamine) is a low-molecular-weight substance with an indole ring in its structure. Tryptophan is a precursor to melatonin biosynthesis, and it exists in all living organisms, from bacteria to mammals. The level of melatonin in plants varies from one species to another, and also among varieties of a species (Arnao, 2014; Arnao and Hernandez-Ruiz, 2015). Previous studies had demonstrated the protective impacts of melatonin in mitigating biotic and abiotic stresses such as pathogen invasion, chilling stress, extreme temperature, extra copper, intense light, salinity, drought and senescence (Arnao and Hernandez-Ruiz, 2014; Manchester et al., 2000; Wang et al., 2013a). Melatonin has both hydrophilic and lipophilic nature and can pass through morphophysiological barriers easily, so it is quickly transported into cells (Galano et al., 2011; Tan et al., 2012). The major functions of melatonin are as a growth promoter, the first line of defence against oxidative damage, and as an antioxidant molecule (Arnao and Hernandez-Ruiz 2014, Hernandez-Ruiz et al. 2004, Hernandez-Ruiz and Arnao 2008). Melatonin protects biological tissues through direct ROS scavenging or by regulating the activity and biosynthesis of enzymes and nonenzymes antioxidant, so it alleviates oxidative damage to lipids, proteins and nucleic acids ( $\mathrm{Li}$ et al., 2015). The positive effects of melatonin on reducing oxidative damage induced by water deficit have been proved in Cucumis sativus (Zhang et al., 2014), Malus species (Li et al., 2015; Wang et al., 2013a), Glycine max (Wei et al., 2015), Lupinus albus (Arnao and Hernandez-Ruiz, 2007) and Vitis vinifera (Meng et al., 2014). Application of exogenous melatonin enables plants to remain alive under abiotic stresses through improvement of the recovery potential (Tan et al., 2012).

Moldavian balm or dragonhead (Dracocephalum moldavica) is a herb of the family Lamiaceae (Hussein et al., 2006). The effective substances of its vegetative organs are sedative and appetizing. Its essence is antibacterial and is consumed for curing stomachache, liver disorders, headache and flatulence, as well as being used by food industries, soda manufacturing and health and make-up industries (Hussein et al., 2006). Although the effects of water stress on crops have been comprehensively studied, there have been limited investigations on the behaviour of aromatic and medicinal herbs under drought stress conditions. Various environmental factors, such as water stress, affect the growth of pharmaceutical plants (Letchamo and Gosselin, 1996). Moldavian balm, with its high susceptibility to drought stress (Alaei et al., 2013), is an important medicinal and economic plant. Considering the lack of rainfall and the occurrence of drought stress in most regions of Iran, the application of plant growth promoter (such as melatonin) to help plants survive and produce optimal yields can be a promising approach which will allow the cultivation of medicinal plants in arid and low-water areas. The main objective of this research was to investigate the effect of foliar application of melatonin on the morphophysiological parameters of the Moldavian balm plant under drought stress. In this regard, we studied different aspects of plant responses, including the antioxidant defence system as well as some biochemicals such as proline and photosynthetic pigments besides 
the morphological traits of plants. The obtained results can be beneficial in learning the physiological and biochemical mechanisms of melatonin action in plants that enable them to cope with drought stress.

\section{MATERIAL AND METHODS}

\section{Plant material}

This study was carried out at the research greenhouse of the Bardsir College of Agriculture, Kerman, Iran (29.55'39"N, 56 $\left.34^{\circ} 20^{\prime \prime} \mathrm{E}\right)$ on April 26, 2016. The experiment was carried out as a completely randomized design in a factorial arrangement with 16 treatments and four replications. Seeds of Dracocephalum moldavica (Isfahan Seedlings and Seeds Co.) grown in plastic pots containing loamysandy soil under the temperature regime of $25 / 22^{\circ} \mathrm{C}$ (day/night) and the light/dark period of $14 / 10 \mathrm{~h}$ were irrigated daily with water under a relative humidity of $60 \%$. After five weeks of growth under normal conditions, three healthy and uniform plants per pot were selected for foliar application of melatonin and four watering regimes. After optimizing melatonin concentrations, experimental treatments including $0,50,100$ and $150 \mu \mathrm{M}$ of melatonin in distilled water and drought stress at four levels of 100, 80, 60 and $40 \%$ of field capacity (FC) were applied to plants, and Tween-20 was used as a surfactant. Approximately $30 \mathrm{ml}$ of melatonin was sprayed on each plant. The melatonin treatments were applied based on the design plan two times a week. To reach the desired watering regimes, the pots were weighed every 2 days until the water content dropped to $80 \%, 60 \%$ and $40 \%$ of field capacity. When $15 \%$ of the plants reached the flowering stage, samples were collected in order to measure the morphological and physiological traits. Leaf length (the average length of 12 randomly selected leaves from the lower, middle and upper parts of the plants of each replication), leaf area (using a leaf area meter, model WinArea-UT-11, Iran), number of lateral branches and flower length were measured as morphological parameters. To analyze physiological traits, leaf samples were frozen in liquid nitrogen and stored at $-80^{\circ} \mathrm{C}$ until laboratory experiments.

\section{Estimation of total chlorophyll (Chl. T)}

The Lichtenthaler method (1987) was used to determine the chlorophyll content. $0.1 \mathrm{~g}$ fresh leaves of Moldavian balm was extracted in $80 \%$ acetone. After filtration, its absorption was read with a UV-Visible Spectrophotometer (Cary 50; Varian
Instruments, Walnut Creek, USA) at wavelengths of $646.8,663.2$ and $470 \mathrm{~nm}$.

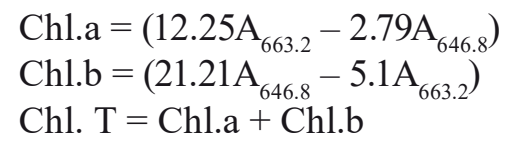

\section{Leaf relative water content ( $R W C$ )}

RWC was calculated as follows:

RWC $=[$ fresh weight - dry weight $) /$ (saturated weight - dry weight) $] \times 100$ (Wheutherley, 1950) .

\section{Electrolyte leakage}

To measure membrane damage, electrolyte leakage was calculated by the Ben Hamed et al. (2007) method. After washing with distilled water to clean the probable ions from the surface of the leaves, $0.2 \mathrm{~g}$ fresh leaves of the plant in $10 \mathrm{~mL}$ of double distilled water were incubated in a bain-marie at $32^{\circ} \mathrm{C}$ for $2 \mathrm{~h}$. The primary electrical conductivity of the samples $\left(\mathrm{EC}_{1}\right)$ was measured with an $\mathrm{EC}$ meter (model Metrohm, Germany). In order to release all the electrolytes, samples were autoclaved at $121^{\circ} \mathrm{C}$ for $20 \mathrm{~min}$. After cooling the test tubes to $25^{\circ} \mathrm{C}$, the secondary electrical conductivity of the samples $\left(\mathrm{EC}_{2}\right)$ was re-measured and the following formula was used to calculate electrolyte leakage:

$\mathrm{EL}=\left(\mathrm{EC}_{1} / \mathrm{EC}_{2}\right) \times 100$

\section{Hydrogen peroxide content}

$\mathrm{H}_{2} \mathrm{O}_{2}$ content was calculated via the method of Velikova et al. (2000). Leaf samples were extracted with $5 \mathrm{ml}$ of $0.1 \%$ trichloroacetic acid (TCA) and then centrifuged at $12,000 \times \mathrm{g}$ for $15 \mathrm{~min} .0 .5 \mathrm{ml}$ of supernatant was combined with $1 \mathrm{ml}$ of $1 \mathrm{M}$ potassium iodide and $0.5 \mathrm{ml}$ of $10 \mathrm{mM}$ phosphate buffer ( $\mathrm{pH}$ 7.0), and sample absorption was read at $390 \mathrm{~nm}$. The $\mathrm{H}_{2} \mathrm{O}_{2}$ content was estimated using the extinction coefficient $(\varepsilon) 0.28 \mathrm{mM} \mathrm{cm}^{-1}$ and expressed as $\mu \mathrm{M} \mathrm{g}^{-1} \mathrm{DW}$.

\section{Thiobarbituric acid reactive substance (TBARS)}

The amount of lipid peroxidation products was measured according to the method of Heath and Packer (1969). $100 \mathrm{mg}$ of Moldavian balm leaf tissues were homogenized in $0.1 \%$ TCA $(\mathrm{W} / \mathrm{V})$, then centrifuged at $10,000 \times \mathrm{g}$ for $15 \mathrm{~min}$. $1 \mathrm{ml}$ of supernatant was added to $5 \mathrm{ml}$ of $20 \%$ TCA $(\mathrm{W} / \mathrm{V})$ solution containing $0.5 \%$ 2-thiobarbituric acid (TBA) (W/V), and the mixture was heated for $30 \mathrm{~min}$. at $90^{\circ} \mathrm{C}$. The samples were quickly immersed in ice for $5 \mathrm{~min}$. and then re-centrifuged for $10 \mathrm{~min}$. at $10,000 \times \mathrm{g}$. For MDA measurement, the absorbance of the supernatant was read at 
$532 \mathrm{~nm}$ and correction for non-specific pigments was performed by deducting the absorbance of the same at $600 \mathrm{~nm}$. The extinction coefficient $(\varepsilon)$ of $1.55 \times 10^{5} \mathrm{M}^{-1} \mathrm{~cm}^{-1}$ was used to determine the MDA concentration (Heath and Packer, 1969). The extinction coefficient of $0.457 \times 10^{5} \mathrm{M}^{-1} \mathrm{~cm}^{-1}$ was used to calculate the concentration of other aldehydes (Meirs et al., 1992).

\section{Enzyme extraction and activity determination}

$0.5 \mathrm{~g}$ of leaf samples was homogenized in $50 \mathrm{mM}$ potassium phosphate buffer ( $\mathrm{pH}$ 7.0) containing $1 \mathrm{mM}$ ethylene diamine tetra acetic acid (EDTA), $1 \%$ soluble polyvinyl pyrrolidone (PVP) and $1 \mathrm{mM}$ phenylmethylsulfonyl fluoride (PMSF), with the addition of $10 \mathrm{mM}$ ascorbic acid that is related to the APX assay. All extraction steps were carried out in ice at $4^{\circ} \mathrm{C}$. The mixture was centrifuged at 20,000 $\times \mathrm{g}$ for $20 \mathrm{~min}$., and the supernatant was used for estimating the activity of antioxidant enzymes and protein content.

\section{Superoxide dismutase (SOD) (EC 1.15.1.1)}

SOD activity was determined according to the method of Giannopolitis and Ries (1977) by monitoring its ability to inhibit the photochemical decrease of nitroblue tetrazolium (NBT). One unit of SOD activity was determined as the amount of enzyme needed to cause $50 \%$ inhibition of the reduction in NBT as monitored at $560 \mathrm{~nm}$.

\section{Catalase (CAT) activity (EC 1.11.1.6)}

Measurement of catalase activity was performed by calculating the reduction in $\mathrm{H}_{2} \mathrm{O}_{2}$ absorption at $240 \mathrm{~nm}$ and using the Dhindsa et al. (1981) method. The reaction mixture contained $50 \mathrm{mM}$ potassium phosphate buffer ( $\mathrm{pH} 7$ ) and $15 \mathrm{mM}$ hydrogen peroxide. The reaction was started by adding 100 $\mu 1$ of the enzyme extract to the reaction mixture. The amount of $\mathrm{H}_{2} \mathrm{O}_{2}$ in the reaction mixture was estimated after 1 minute by using the extinction coefficient of $40 \mathrm{mM}^{-1} \mathrm{~cm}^{-1}$, which indicated the activity of the catalase enzyme.

\section{Guaiacol peroxidase (GPX) activity (EC 1.11.1.7)}

Guaiacol was used as a substrate to evaluate the activity of GPX. The reaction mixture consisted of $50 \mathrm{mM}$ phosphorus buffer ( $\mathrm{pH} 7)$, hydrogen peroxide $(1 \%)$ and guaiacol (4\%). The reaction was started by adding $20 \mu 1$ of enzyme extract to the reaction mixture at $25^{\circ} \mathrm{C}$. The increase in absorbance at $470 \mathrm{~nm}$ due to guaiacol oxidation was recorded for 3 min. (Zhang et al., 2005).

\section{Ascorbate peroxidase (APX) activity (EC 1.11.1.11)}

Ascorbate peroxidase was measured according to the oxidation of ascorbate (ASA). The reaction mixture contained $50 \mathrm{mM}$ potassium phosphate buffer ( $\mathrm{pH} 7.0$ ), $0.5 \mathrm{mM}$ ascorbate, $0.1 \mathrm{mM} \mathrm{H}_{2} \mathrm{O}_{2}$ and $150 \mu 1$ enzyme extract. The amount of ascorbate oxidation was recorded after 2 minutes by measuring the decrease in absorbance at $290 \mathrm{~nm}$ and using the extinction coefficient $(\varepsilon)$ of $2.8 \mathrm{mM}^{-1} \mathrm{~cm}^{-1}$ (Nakano and Asada, 1981).

\section{Total soluble proteins}

Protein content was calculated by the method of Bradford (1976), in which Bovine serum albumin was used as a standard.

\section{Proline determination}

$500 \mathrm{mg}$ of leaf tissue was homogenized in $7.5 \mathrm{ml}$ of sulfosalicylic acid (3\%) and then centrifuged. $2 \mathrm{ml}$ of extract was mixed with $2 \mathrm{ml}$ of glacial acetic acid and $2 \mathrm{ml}$ of ninhydrin reagent. The reaction mixture was heated at $100^{\circ} \mathrm{C}$ for $1 \mathrm{~h}$. After this time, the tubes containing the mixture were placed in a cold-water bath to stop all reactions. Then, $4 \mathrm{ml}$ of toluene was added to the mixture and the tubes were well vortexed. Then, the estimation of proline content was performed based on the method of Bates

Table 1. Mean squares (MS) for morphological traits, including leaf length, leaf surface area, number of lateral branches and flower length of Dracocephalum moldavica

\begin{tabular}{lccccc}
\hline Sources of variance & $\begin{array}{c}\text { Degrees } \\
\text { of } \\
\text { freedom }\end{array}$ & $\begin{array}{c}\text { Leaf length } \\
(\mathrm{cm})\end{array}$ & $\begin{array}{c}\text { Leaf surface area } \\
\left(\mathrm{mm}^{2} \text { per plant }\right)\end{array}$ & $\begin{array}{c}\text { Number of lateral } \\
\text { branches }\end{array}$ & $\begin{array}{c}\text { Flower length } \\
(\mathrm{cm})\end{array}$ \\
\hline Melatonin & 3 & $0.091^{\text {ns }}$ & $2904.29^{* *}$ & $43.712^{* *}$ & $7.67^{* *}$ \\
Drought stress & 3 & $0.753^{* *}$ & $32245.45^{* *}$ & $511.41^{* *}$ & $125.27^{* *}$ \\
Melatonin $\times$ Drought stress & 9 & $0.033^{\text {ns }}$ & $527.05^{\text {ns }}$ & $8.214^{* *}$ & $1.08^{*}$ \\
Error & 48 & 0.065 & 512.94 & 0.369 & 0.411 \\
CV\% & & 6.19 & 7.71 & 4.03 & 5.83 \\
\hline
\end{tabular}

$* *, *$ and ns denote significant differences at $0.01,0.05 \%$ levels, and not significant, respectively 
et al. (1973), and the absorbance was determined at $520 \mathrm{~nm}$.

\section{Statistical analysis}

Statistical analyses were accomplished by one-way ANOVA using the LSD test to determine whether the means were significantly different, taking $p<0.05$ as significant. The statistical analyses and computations were performed using SAS and MSTATC.

\section{RESULTS AND DISCUSSION}

Foliar application of $100 \mu \mathrm{M}$ melatonin was more effective compared with the concentrations of 50 and $150 \mu \mathrm{M}$ melatonin, especially under moderate and severe drought stress. Therefore, based on the obtained results, we focused on the best concentration of melatonin $(100 \mu \mathrm{M})$.

The results obtained from the variance analysis of data are given in tables 1 and 2 . The results showed that drought stress had a significant ( $p \leq$ 0.01 ) effect on leaf length and area, the number of lateral branches and flower length (Tab. 1). The interaction between melatonin and drought stress was significant for the number of lateral branches $(p \leq 0.01)$ and flower length $(p \leq 0.05)$ (Tab. 1). Application of melatonin and drought stress had a significant effect on Chl. T, RWC, EL, $\mathrm{H}_{2} \mathrm{O}_{2}$, MDA, other aldehydes, GPX and APX activities $(p \leq 0.01)$ (Tab. 2). Water stress $(p \leq 0.01)$ and foliar application of melatonin $(p \leq 0.05)$ significantly affected proline content, SOD and CAT activities (Tab. 2).

The highest level of drought stress reduced Chl. T by approximately $55.57 \%$ compared to the control (Tab. 3). Foliar application of 50 and $100 \mu \mathrm{M}$ melatonin caused an increment of $7.65 \%$ and $18.8 \%$ in Chl. T, respectively, compared to the control under 40\% FC drought stress (Tab. 3). Chl. T decreased approximately $3.73 \%$ at the concentration of $150 \mu \mathrm{M}$ melatonin compared with plants which were sprayed with distilled water under the highest level of drought stress (Tab. 3).

Several studies have highlighted the dual function of melatonin in plants as a growth regulator improving growth and development (Arnao and Hernandez-Ruiz, 2014) and as a protector against biotic and abiotic stresses at low-dose ( $\mathrm{Li}$ et al., 2012; Manchester et al., 2000). The natural antioxidant capacity of melatonin makes it a beneficial candidate for use as a biostimulant for agricultural goals and enhances the plant's ability to cope with environmental stresses (Arnao,

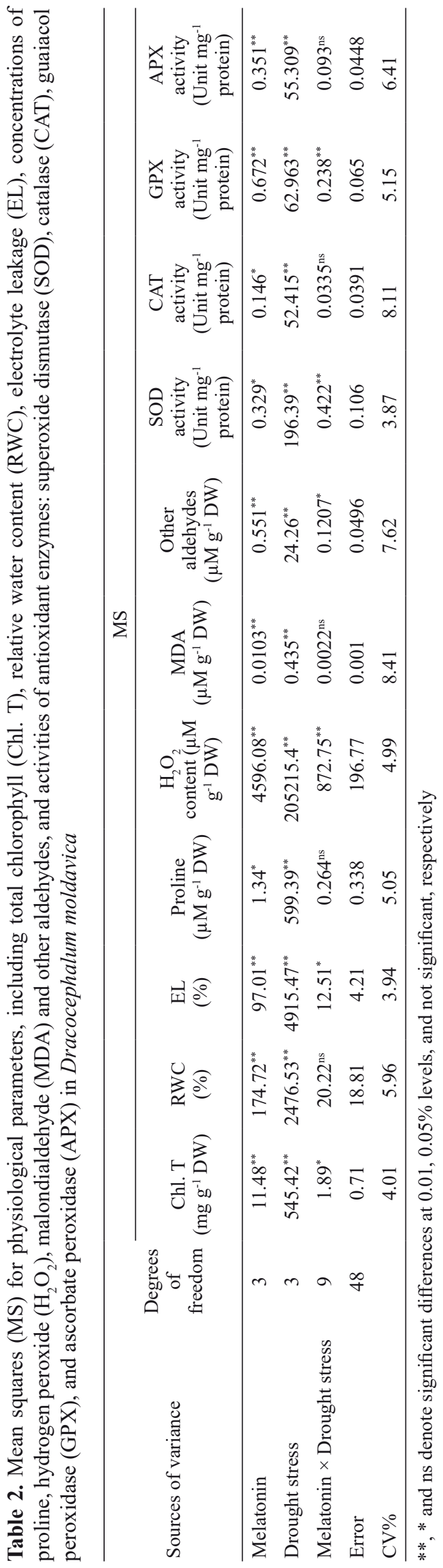




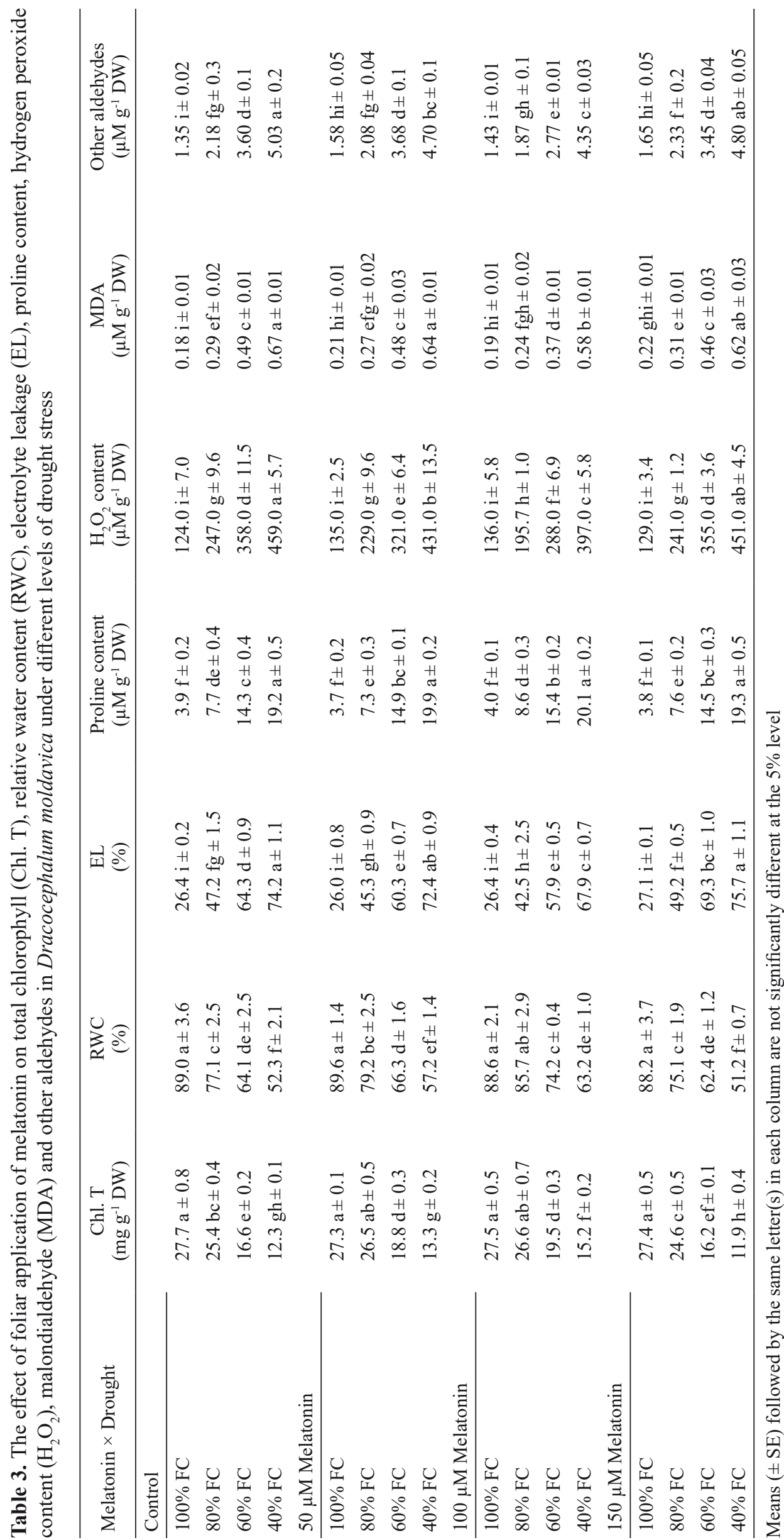


2014; Arnao and Hernandez-Ruiz, 2014; Janas and Posmyk, 2013; Zhang et al., 2013, 2014; Wang et al., 2013a). However, the exact mechanisms by which melatonin ameliorates the adverse effects of drought stress is still not fully elucidated ( $\mathrm{Li}$ et al., 2015). In this research, we examined the possible adaptation of Moldavian balm plants to drought stress through foliar application of different concentrations of melatonin by assessing a number of morphophysiological and biochemical indices related to drought adaptation. Our results showed that foliar application of melatonin improved the responses of Moldavian balm plants under drought stress in terms of morphological traits and physiological and biochemical parameters. Similar results under drought stress had also been reported by Li et al. (2015), Liu et al. (2015), Cui et al. (2017) and Ye et al. (2016). Drought stress caused a decrement in photosynthetic pigments, but the $100 \mu \mathrm{M}$ melatonin treatment increased Chl. (as the main part of photosynthetic structure) in stress conditions (Tab. 3). Our findings are in agreement with the results of other researchers showing that melatonin application improves drought tolerance in wheat, tomato, maize and cucumber seedlings (Cui et al., 2017; Liu et al., 2015; Ye et al., 2016; Zhang et al., 2013). Chlorophyll photo oxidation, degradation of chloroplast structure and photosynthetic apparatus, inhibition of Chl. biosynthesis, degradation of chlorophyll synthesis precursors and increase in chlorophyllase activity are the reasons for the reduction in photosynthetic pigments under drought stress (Wang et al., 2013a). Melatonin at different concentrations caused a delay in chlorophyll loss and leaf senescence compared to the control plants (Arnao and HernandezRuiz, 2009). Long-term exogenous application of

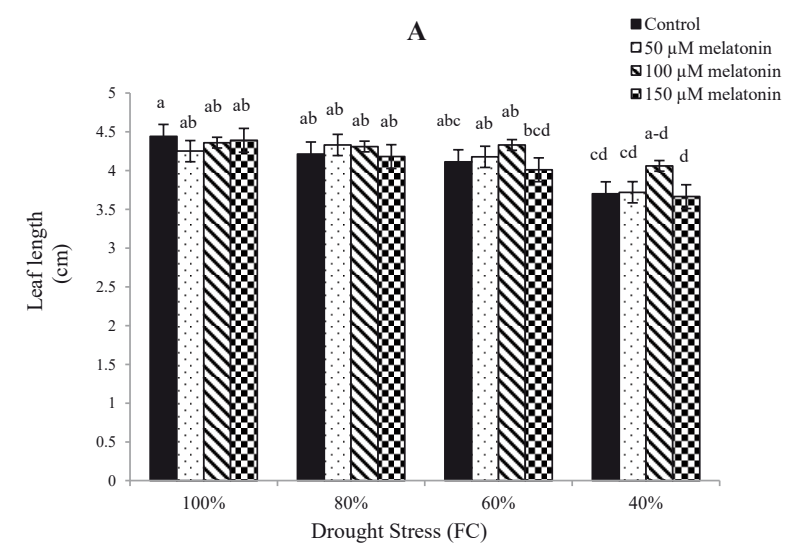

melatonin to one-year-old Malus $s p$. trees under drought stress conditions delayed leaf senescence, with a significant reduction in chlorophyll degradation, through the enhancement of ROS scavenging enzyme activities (Wang et al., 2013a, 2013b). Exogenous melatonin postponed induced senescence in Hordeum vulgare leaves and delayed the loss of chlorophylls compared with untreated plants. The cited authors inferred that those results could have been related to the interactive effect of melatonin and other plant growth regulators such as ABA and kinetin (a synthetic cytokinin with plant hormone activity) on foliar senescence (Arnao and Hernandez-Ruiz, 2015, 2017b).

Foliar application of $100 \mu \mathrm{M}$ melatonin markedly alleviated the adverse effects of water stress. The response of RWC to the interaction of melatonin concentrations and drought levels varied (Tab. 3). RWC increased $8.57 \%$ and $17.2 \%$ at the concentrations of 50 and $100 \mu \mathrm{M}$ melatonin, respectively, compared with the control plants under severe drought stress, while the concentration of $150 \mu \mathrm{M}$ melatonin caused a reduction of $2.1 \%$ in RWC compared to non-treated plants under drought stress of $40 \%$ FC (Tab. 3). The highest level of drought stress $(40 \%$ FC) caused a reduction of $16.67 \%$ and $38.5 \%$ in leaf length and leaf surface area, respectively, as compared to the control (Fig. 1). No significant difference was observed in leaf length between any concentration of melatonin and the control under both conditions (Fig. 1A). The concentration of $100 \mu \mathrm{M}$ melatonin produced a significant difference in leaf surface area compared with the other levels of melatonin and non-treated plants under moderate $(60 \% \mathrm{FC})$ and severe (40\% FC) drought stress (Fig. 1B). The response of the number of lateral branches to the

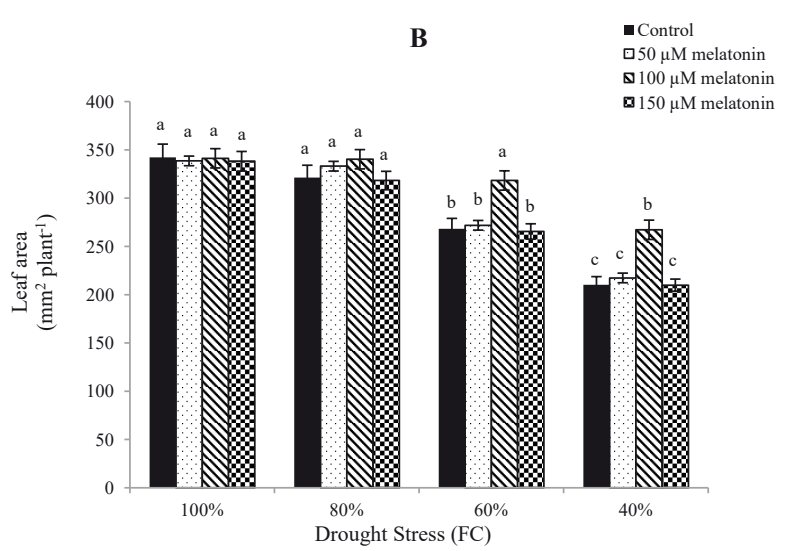

Figure 1. Effect of melatonin treatment on leaf length (A) and leaf surface area (B) of Moldavian balm plants under drought stress. The mean comparisons were performed using the LSD method at $p \leq 0.05$ significance level. Means $( \pm \mathrm{SE})$ followed by the same letter(s) are not significantly different 


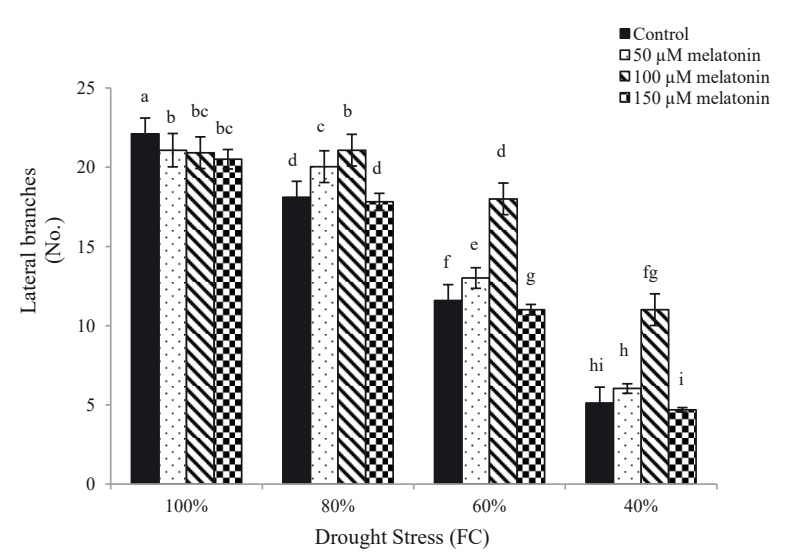

Figure 2. Effect of melatonin treatment on the number of lateral branches of Moldavian balm plants under drought stress. The mean comparisons were performed using the LSD method at $p \leq 0.05$ significance level. Means $( \pm \mathrm{SE})$ followed by the same letter(s) are not significantly different

interaction of melatonin concentrations and drought levels varied, with the highest number of lateral branches observed in the control (22.11) (Fig. 2). At the concentration of $100 \mu \mathrm{M}$ melatonin, the number of lateral branches was increased by approximately $53.5 \%$ compared to non-treated plants under $40 \%$ FC drought stress (Fig. 2). The data indicated that drought treatment at the levels of $60 \%$ and $40 \% \mathrm{FC}$ caused a reduction of $31.51 \%$ and $54.9 \%$ in flower length, respectively, compared with the control (Fig. 3). It seems that the concentration of $100 \mu \mathrm{M}$ melatonin was more effective in enhancing this trait at all levels of drought stress (Fig. 3).

Our findings showed that drought stress had a negative effect on RWC, and treatment with melatonin alleviated the adverse effect of water stress (Tab. 3). Similar results under drought stress had been reported for Malus hupehensis (Wang et al., 2013b) and Cucumis sativus (Zhang et al., 2013). An increase in water viscosity and decrease in membrane fluidity caused a reduction in water influx through the roots under water stress conditions (Wu et al., 2012). Consequently, the state of turgor gradually decreased in cells, and the cells began to shrink. Simultaneously, plants reduced the surface area of their leaves, leaf length and the number of lateral branches to prevent water loss ( $\mathrm{Wu}$ et al., 2012). This precautionary approach is one of the first responses of plants to cope with water deficit (Maksup et al., 2014). In addition, RWC is one of the indices for plant tolerance to drought stress, and the regulation of RWC is also related to plant adaptation to this type of stress (Turk et al., 2014). This study demonstrated that the decreases in RWC in plants

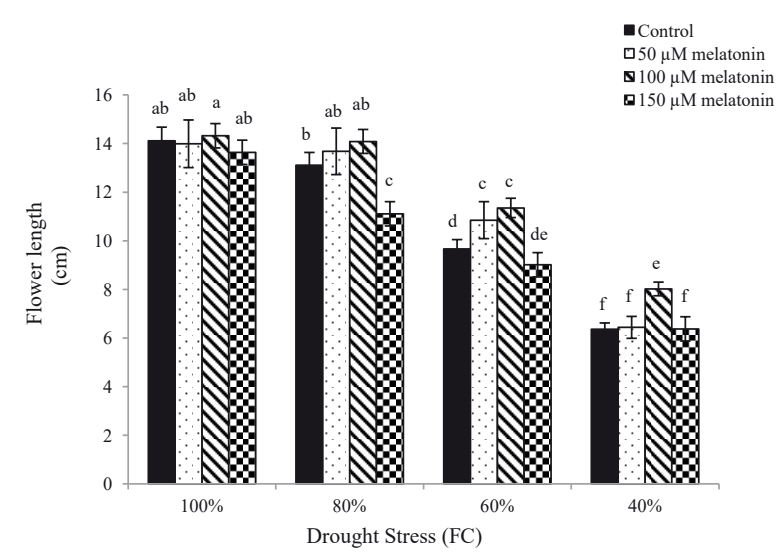

Figure 3. Effect of melatonin treatment on flower length of Moldavian balm plants under drought stress. The mean comparisons were performed using the LSD method at $p \leq 0.05$ significance level. Means $( \pm \mathrm{SE})$ followed by the same letter(s) are not significantly different

which were subjected to drought stress were ameliorated by the exogenous application of $100 \mu \mathrm{M}$ melatonin, and also indicated that this concentration of melatonin could substantially reduce the damage induced by water stress. This ameliorating role of melatonin may be related to its direct and/or indirect effect on inhibiting injury to membranes (Turk et al., 2014). The larger leaf surface area, excess lateral branches and maximum flower length in melatonintreated plants (especially with the concentration of $100 \mu \mathrm{M})$ clearly explain the mitigating effect of melatonin on RWC. Melatonin enhanced drought and salt tolerance in soybean plants was evident from the increased leaf length and leaf surface area, and a reduction of biomass lost when exposed to these stresses (Wei et al., 2015). Our results are in accordance with the report showing that melatonin at low concentrations increased vegetative growth and development of Glycyrrhiza uralensis (Afreen et al., 2006) and Prunus avium (Sarropoulou et al., 2012). Melatonin as a biostimulant has been proven to affect plant metabolites and stimulate biosynthesis of phytohormones, facilitate nutrient absorption, improve plant root water uptake ability, stimulate root and shoot growth, and finally enhance the quality and quantity of production and provide a much greater supply of assimilates to growing tissue (Arnao and Hernandez-Ruiz, 2007; Arnao and Hernandez-Ruiz, 2017a, 2017b; Ye et al., 2016). Exogenously applied melatonin affects developmental processes during both vegetative and reproductive growth. The structure of auxin is similar to that of melatonin, so it seems that the role of melatonin in plants is the same as of this 
hormone (Janas and Posmyk, 2013). Promotion of plant growth in Lupinus albus (Hernandez-Ruiz et al., 2004) and some monocot plants (HernandezRuiz et al., 2005) and regulation of the growth of roots, shoots, and explants, and activation of seed germination and rhizogenesis (Arnao, 2014) have shown that melatonin could have an auxin-like activity (Arnao and Hernandez-Ruiz, 2017b). Electrolyte leakage was measured to evaluate the effect of drought stress on membrane permeability. Drought stress caused an increase in EL to intercellular space so that at $40 \% \mathrm{FC}$ it caused an increase of $64.5 \%$ in EL compared to the control (100\% FC). EL decreased by approximately $8.5 \%$ in the plants which were sprayed with the concentration of $100 \mu \mathrm{M}$ melatonin compared to the control under severe drought stress (Tab. 3). The highest level of drought stress ( $40 \%$ FC) caused an increase of $72 \%$ in $\mathrm{H}_{2} \mathrm{O}_{2}$ content as compared to the control (Tab. 3). The concentration of $100 \mu \mathrm{M}$ melatonin markedly alleviated the effects of drought stress (Tab. 3). Melatonin at the concentration of $100 \mu \mathrm{M}$ had a significant difference in comparison with non-treated plants and other levels of melatonin in $\mathrm{H}_{2} \mathrm{O}_{2}$ content under all levels of drought stress (Tab. 3). The indicator of lipid peroxidation related to the measurement of MDA and other aldehydes. The highest and the lowest concentration of MDA and other aldehydes were recorded for the control and drought stress of $40 \% \mathrm{FC}$ treatments, respectively (Tab. 3). At all the concentrations used in this study, melatonin had no significant impact on aldehyde content compared to non-treated plants under normal conditions (Tab. 3). Among the melatonin concentrations, only the concentration of $100 \mu \mathrm{M}$ melatonin applied through foliar spraying was more effective at both levels (60\% and $40 \%$ FC) of drought stress (Tab. 3).

In the present investigation, water deficit significantly increased the generation of $\mathrm{H}_{2} \mathrm{O}_{2}$, electrolyte leakage, and the concentrations of MDA and other aldehydes in the leaves. Drought stress induced lipid peroxidation by the production of ROS (Shi et al., 2007), thus making the membranes leaky as evidenced by the increased electrolyte leakage. Membrane damage increased with the increment in the intensity and duration of stress. Melatonin alleviated the adverse effect of drought stress in Moldavian balm plants (Tab. 3). Increased concentrations of $\mathrm{H}_{2} \mathrm{O}_{2}$ lead to lipid peroxidation, which causes membrane damage and electrolyte leakage (Cui et al., 2017). Several studies have reported that the role of melatonin in the prevention of lipid peroxidation is dependent on its ability to react with lipid peroxyl (LOO') and lipid alcoxyl (LO') radicals and interrupt the peroxidation chain (Sarropoulou et al., 2012; Li et al., 2012; Zhang et al., 2013). The comparative rates of lipid peroxidation were evaluated in the leaves of the control and drought-treated Moldavian balm plants through the measurement of the levels of MDA and other aldehydes (Tab. 3). The concentrations of MDA and other aldehydes were similar between the control samples and all the concentrations of melatonin under normal conditions. Upon drought imposition, the levels of MDA and other aldehydes increased in non-melatonin treated plants, showing a decrease in TBARS content (Tab. 3). A protective effect of melatonin on membrane damage has been reported under water deficit (Meng et al., 2014; Zhang et al., 2013; Wang et al., 2013a). The reduction in the level of electrolytes (Tab. 3) and the decrease in TBARS concentration proved the protective role of melatonin in membrane injury induced by water stress. The response of proline content to the interaction of melatonin concentrations and drought levels were similar under normal conditions and the highest level of water stress (Tab. 3). The concentration of $100 \mu \mathrm{M}$ melatonin without any difference from the control showed a significant difference with the concentrations of 50 and $150 \mu \mathrm{M}$ melatonin under drought stress of $80 \%$ FC (Tab. 3). The difference in proline content was not statistically significant among the different concentrations of melatonin under moderate level of drought stress $(60 \% \mathrm{FC})$ (Tab. 3).

Metabolic acclimation through the synthesis, accumulation, and temporary increase of compatible solutes (e.g., proline, betaine, glycine, mannitol, soluble sugar, soluble protein) are considered basic strategies for neutralizing drought stress symptoms by either conserving the vital enzymes and cellular macro-molecular structures or detoxifying free radicals. Water stress increased the endogenous levels of sugars, proline and other osmolytes (Meng et al., 2014), referring to its involvement in influencing the process of osmoregulation. Except for the concentration of $100 \mu \mathrm{M}$ melatonin under moderate drought stress, the other groups of melatonin did not have any significant effect on proline content as compared to the control (Tab. 3). These results contradict previous reports claiming that the proline content increased in melatonintreated plants (Antoniou et al., 2017; Arnao and Hernandez-Ruiz, 2009, 2014, 2015; Meng et al., 2014; Sarropoulou et al., 2012). Therefore, it 

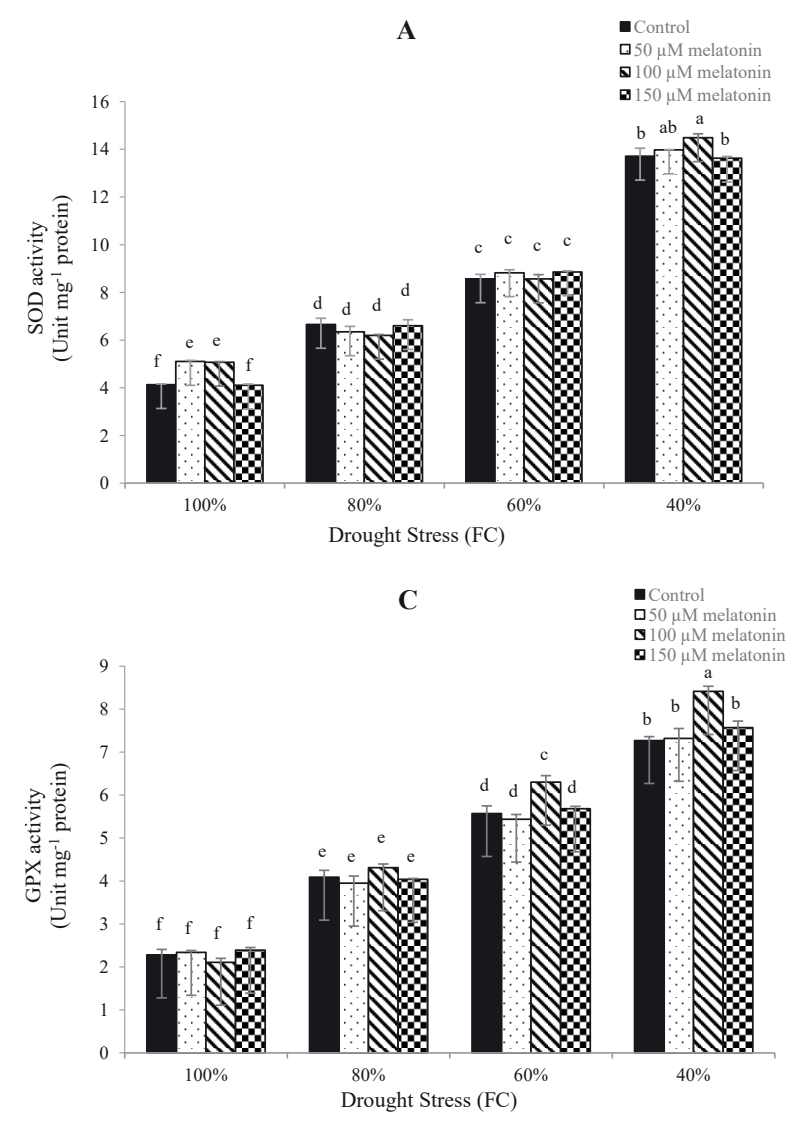
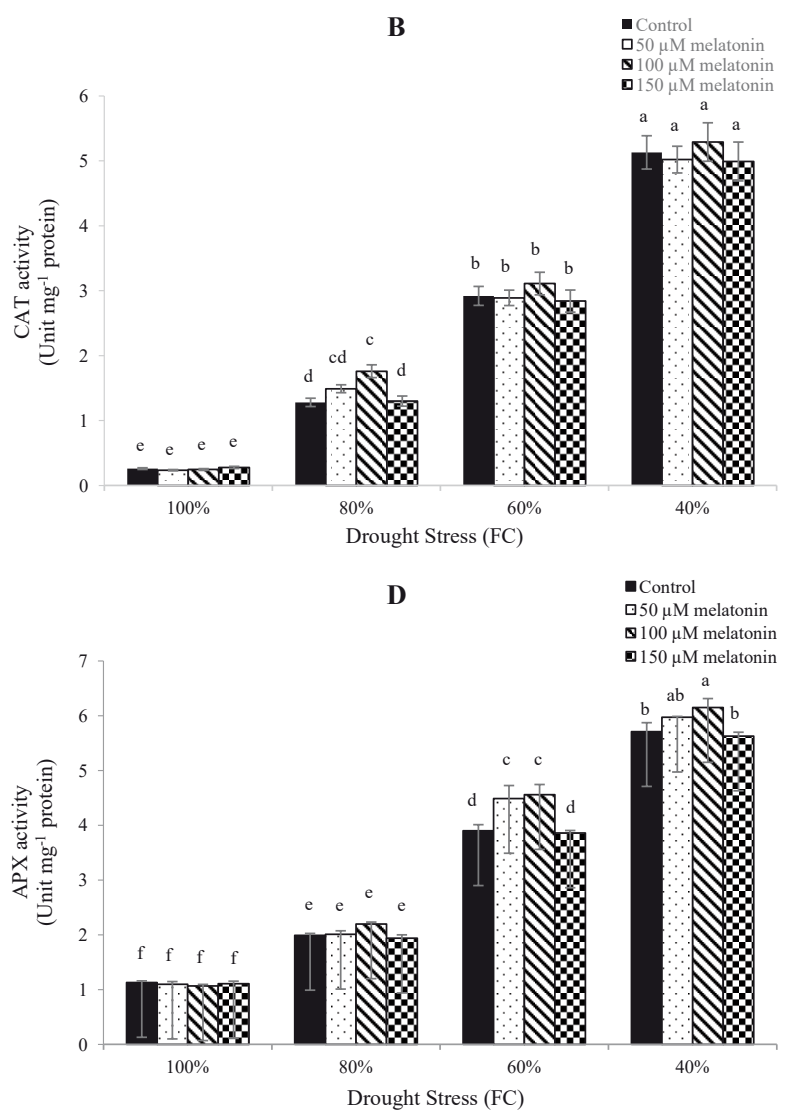

Figure 4. Effect of melatonin treatment on the activity of antioxidant enzymes, including A - superoxide dismutase (SOD), B - catalase (CAT), C - guaiacol peroxidase (GPX), and D - ascorbate peroxidase (APX), in Moldavian balm plants under drought stress. The mean comparisons were performed using the LSD method at $p \leq 0.05$ significance level. Means $( \pm \mathrm{SE})$ followed by the same letter(s) are not significantly different

seems that the protective effect of melatonin on Moldavian balm plants was achieved through other mechanisms.

Changes in the specific activity of antioxidant enzymes is the consequence of oxidative stress. The effect of drought stress on SOD, CAT, GPX and APX in Moldavian balm leaves, either with or without melatonin treatment, was determined. The results showed that the activity of SOD, CAT, GPX and APX increased in drought-stressed plants (especially at $40 \% \mathrm{FC}$ ) rather than in the control groups (Fig. 4). Treatment of plants with $100 \mu \mathrm{M}$ melatonin increased the activity of antioxidant enzymes in those plants which were subjected to the severe drought stress. SOD, CAT, GPX and APX activities were increased by approximately $69.9 \%$, $94.9 \%, 68.6 \%$ and $80.2 \%$ compared to the control under 40\% FC drought stress (Fig. 4). The difference in SOD activity was not statistically significant between 50 and $100 \mu \mathrm{M}$ melatonin treatments, while the concentration of $100 \mu \mathrm{M}$ melatonin produced significantly higher SOD activity than in the control and $150 \mu \mathrm{M}$ melatonin under $40 \% \mathrm{FC}$ drought stress (Fig. 4A). There was no significant difference in
CAT activity between the melatonin treatments and the control under normal conditions and at the levels of $60 \%$ and $40 \%$ FC drought stress (Fig. 4B). Exogenous application of $100 \mu \mathrm{M}$ melatonin caused an increment of $27.3 \%$ in CAT activity as compared to the control plants under mild drought stress (Fig. 4B). On the basis of these results, increasing drought levels markedly raised GPX activity (Fig. 4C). No significant difference was observed in GPX activity between all the concentrations of melatonin and non-treated plants under normal and mild drought stress conditions, while under $60 \%$ and $40 \%$ FC drought stress conditions its values for $100 \mu \mathrm{M}$ melatonin were 6.3 and $8.41 \mathrm{Unit} / \mathrm{mg}$ protein, respectively (Fig. 4C). The data indicated that drought treatment at the levels of $60 \%$ and $40 \%$ FC caused an increment of $71 \%$ and $80.2 \%$ in APX activity, respectively, compared with the control (Fig. 4D). Treatment of Moldavian balm plants with $100 \mu \mathrm{M}$ melatonin had a positive effect on the activity of this enzyme under moderate and severe drought conditions (Fig. 4D).

In Moldavian balm plants under drought stress, SOD, CAT, GPX and APX activities were 
elevated over those in the controls (Fig. 4). Shi et al. (2007) had reported that tolerant genotypes had higher activities of ROS-scavenging enzymes than susceptible ones, so that explained the important role of the antioxidant system in plant tolerance of environmental stresses. Our results indicated that under water stress, the $\mathrm{H}_{2} \mathrm{O}_{2}$ content increased (Tab. 3). In melatonin-treated plants, the $\mathrm{H}_{2} \mathrm{O}_{2}$ content declined, which might be related to the activity of antioxidant enzymes (including SOD, CAT, GPX and APX activities). Melatonin and some of its metabolites are known as endogenous free radical scavengers (Sarropoulou et al., 2012; Zhang et al., 2013) and antioxidants (Zhang et al., 2013) which may directly scavenge $\mathrm{H}_{2} \mathrm{O}_{2}$ (Cui et al., 2017). One of the main functions of melatonin, along with the activities of CAT, GPX and APX, may be to preserve intracellular $\mathrm{H}_{2} \mathrm{O}_{2}$ concentrations at steadystate levels (Cui et al., 2017). Exogenous application of melatonin inhibited $\mathrm{H}_{2} \mathrm{O}_{2}$ accumulation through direct ROS-scavenging and enhancement of CAT, GPX and APX activities. These results could be explained by two mechanisms. First, melatonin is a broad-spectrum antioxidant and a receptorindependent free radical scavenger (Arnao and Hernandez-Ruiz, 2014). Second, it could stimulate the activities of antioxidant enzymes or induced other antioxidants to protect plants which were exposed to oxidative stress (Galano et al., 2011; Ye et al., 2016). SOD, GPX and APX showed significant rises in activity following the treatment with $100 \mu \mathrm{M}$ melatonin. The primary role of SOD in the protection of cells against oxidative damage induced by drought stress have been proved (Sharma and Dubey, 2007). SOD activity increased significantly in Moldavian balm plants which were subjected to $100 \mu \mathrm{M}$ melatonin under water deficit (Fig. 4A). Zhao et al. (2011) had proposed that melatonin protected Rhodiola crenulata cells against oxidative stress during cryo-preservation by increasing SOD and CAT activities. However, the physiological and molecular mechanisms of exogenous melatonin application which ameliorate drought tolerance of plants have not been fully clarified. Considering the positive effects of melatonin on increasing plant tolerance to drought stress, it is expected that the application of melatonin in agriculture will lead to an increase in the quality and quantity of yields and enhance plant development. Since melatonin is an inexpensive and eco-friendly substance, its application as a biostimulant could be a useful and affordable method for agricultural purposes to reduce the adverse effects of stresses and promote plant growth and development under different conditions (Arnao and Hernandez-Ruiz, 2015; Hernandez-Ruiz and Arnao, 2016).

\section{CONCLUSIONS}

According to the currently available data, exogenous application of melatonin, especially at the concentration of $100 \mu \mathrm{M}$, greatly improves the growth of Moldavian balm plants through the inhibition of membrane injury and reduced concentrations of MDA, other aldehydes and $\mathrm{H}_{2} \mathrm{O}_{2}$ under moderate and severe drought stress. These effects are probably carried out by regulating the activity of antioxidant enzymes such as SOD, CAT, GPX and APX. Reduced oxidative damage and improved water status enable plants to maintain a higher total chlorophyll content and consequently increase leaf expansion, the number of lateral branches and flower length. The concentration of $100 \mu \mathrm{M}$ melatonin had no significant effect on proline content (as an osmoregulator) under mild and severe drought stress. Based on our results, it seems that melatonin alleviates drought stress mostly through activating the antioxidant defence system in Moldavian balm plants rather than via other regulatory pathways such as osmoprotection and proline content. Further studies concerning the details of the method and focused on elucidating the influence of exogenous melatonin on changes in the specific molecular and biochemical pathways will provide new information about the direct and indirect mechanisms of melatonin activity in plants.

\section{FUNDING}

Rozita Kabiri thanks Bardsir College of Kerman, Iran for providing laboratory equipment and facilities.

\section{AUTHOR CONTRIBUTIONS}

A.H., H.O. and F.N. - equally designed the experiment; M.N. - provided greenhouse, laboratory and experimental materials; H.O. and M.N. supervised the laboratory work; R.K. - performed analytical measurements and statistical analyses, and contributed to manuscript writing; Z.T. - helped in statistical analyses; H.O. - revised the manuscript.

\section{CONFLICT OF INTEREST}

Authors declare no conflict of interest. 


\section{REFERENCES}

Afreen F., Zobayed S., Kozai T., 2006. Melatonin in Glycyrrhiza uralensis: Response of plant roots to spectral quality of light and UV-B radiation. J. Pineal Res. 41, 108-115.

Alaei Sh., Melikyan A., Kobraee S., Mahna N., 2013. Effect of different soil moisture levels on morphological and physiological characteristics of Dracocephalum moldavica. Agri. Commun. 1, 23-26.

Antoniou C., Chatzimichail G., Xenofontos R., Pavlou J.J., Panagiotou E., Christou A., Fotopoulos V., 2017. Melatonin systemically ameliorates drought stress-induced damage in Medicago sativa plants by modulating nitro-oxidative homeostasis and proline metabolism. J. Pineal Res. 62, e12401.

ArnaO M.B., 2014. Phytomelatonin: discovery, content, and role in plants. Adv. Bot. 2014, e815769.

Arnao M.B., Hernandez-Ruiz J., 2007. Melatonin promotes adventitious and lateral root regeneration in etiolated hypocotyls of Lupinus albus L. J. Pineal Res. 42, 147-152.

Arnao M.B., Hernandez-Ruiz J., 2009. Chemical stress by different agents affects the melatonin content of barley roots. J. Pineal Res. 46, 295-299.

Arnao M.B., Hernandez-Ruiz J., 2014. Melatonin: plant growth regulator and/or biostimulator during stress? Trends Plant Sci. 19, 789-797.

Arnao M.B., Hernandez-Ruiz J., 2015. Function of melatonin in plants: a review. J. Pineal Res. 59, 133150.

Arnao M.B., Hernandez-Ruiz J., 2017a. Growth activity, rooting capacity, and tropism: three auxinic precepts fulfilled by melatonin. Acta Physiol. Plant. 39, 127.

Arnao M.B., Hernandez-Ruiz J., 2017b. Melatonin in its relationship to plant hormones. Ann. Bot. 121(2), 195-207.

BATES L.S., 1973. Rapid determination of free proline for water stress studies. Plant Soil 39, 205-207.

Ben Hamed K., Castagna A., Salem E., Ranieri A., AbDelly C., 2007. Sea fennel (Crithmum maritimum L.) under salinity conditions: a comparison of leaf and root antioxidant responses. Plant Growth Regul. 53, 185-194.

BRADFORD M.M., 1976. A rapid and sensitive method for the quantitation of microgram quantities of protein utilizing the principle of protein-dye binding. Anal. Biochem. 72, 248-254.

Cui G., Zhao X., Liu S., Sun F., Zhang C., Xi Y., 2017. Beneficial effects of melatonin in overcoming drought stress in wheat seedlings. Plant Physiol. Bioch. 118, 138-149.

Dhindsa R.S., Dhindsa P., Torpe A., 1981. Leaf senescence correlated with increased levels of membrane permeability and lipid peroxidation and decrease levels of superoxide dismutase and catalase. J. Exp. Bot. 32, 93-101.
Galano A., TAn D.X., ReITER R.J., 2011. Melatonin as a natural ally against oxidative stress: a physicochemical examination. J. Pineal Res. 51, 1-16.

Gamze O., Mehmet D.K., Mehmet A., 2005. Effects of salt and drought stresses on germination and seedling growth of pea (Pisum sativum L.). Turk. J. Agri. For. 29, 237-242.

Giannopolitis C.N., Ries S.K., 1977. Superoxide dismutase. I. Occurrence in higher plants. Plant Physiol. 59, 309-314.

Heath R.L., Packer L., 1969. Photoperoxidation in isolated chloroplast: I. kinetics and stoichiometry of fatty acid peroxidation. Arch. Biochem. Biophys. 125, 189-198.

Hernandez-Ruiz J., Arnao M.B., 2008. Melatonin stimulates the expansion of etiolated lupin cotyledons. Plant Growth Regul. 55, 29-34.

Hernandez-Ruiz J., Arnao M.B., 2016. Phytomelatonin, an interesting tool for agricultural crops. Focus Sci. $2,1-7$.

Hernandez-Ruiz J., Cano A., Arnao M.B., 2004. Melatonin: growth-stimulating compound present in lupin tissues. Planta 220, 140-144.

Hernandez-Ruiz J., Cano A., Arnao M.B., 2005. Melatonin acts as a growth-stimulating compound in some monocot species. J. Pineal Res. 39, 137-142.

Hussein M.S., El-Sherheny S.E., Khalil M.Y., NAGuib N.Y., ALY S.M., 2006. Growth characters and chemical constituents of Dracocephalum moldavica L. plants in relation to compost fertilizer and planting distance. Sci. Hortic. 108, 322-331.

Janas K.M., Posmyk M.M., 2013. Melatonin, an underestimated natural substance with great potential for agricultural application. Acta Physiol. Plant. 35, 3285-3292.

Letchamo W., Gosselin A., 1996. Transpiration, essential oil glands, epicuticular wax and morphology of Thymus vulgaris are influenced by light intensity and water supply. J. Hort. Sci. 71, 123-134.

Li C., Tan D.X., Liang D., Chang C., Jia D.F., Ma F.W., 2015. Melatonin mediates the regulation of ABA metabolism, free-radical scavenging and Stomatal behavior in two Malus species under drought stress. J. Exp. Bot. 66, 669-680.

Li C., Wang P., Wei Z., Liang D., Liu C., Yin L., Jia D., Fu M., MA F., 2012. The mitigation effects of exogenous melatonin on salinity-induced stress in Malus hupehensis. J. Pineal Res. 53, 298-306.

LiCHTENTHALER H.K., 1987. Chlorophylls and carotenoids: pigments of photosynthetic biomembranes. Meth. Enzymol. 148, 350-382.

LiU J., Wang W., Wang L., Sun Y., 2015. Exogenous melatonin improves seedling health index and drought tolerance in tomato. Plant Growth Regul. 77, 317-326.

Maksup S., Roytrakul S., Supaibulwatana K., 2014. Physiological and comparative proteomic analyses of Thai jasmine rice and two check cultivars in response to drought stress. J. Plant Interact. 9, 43-55. 
Manchester L.C., TAN D.X., Reiter R.J., PARK W., Monis K., Qi W., 2000. High levels of melatonin in the seeds of edible plants possible function in germ tissue protection. Life Sci. 67, 3023-3029.

Meirs S., Philosophhadas S., Aharoni N., 1992. Ethylene increased accumulation of fluorescent lipid peroxidation products detected during senescence of parsley by a newly developed method. J. Amer. Soc. Hort. Sci. 117, 128-132.

Meng J.F., Xu T.F., Wang Z.Z., Fang Y.L., Xi Z.M., ZHANG Z.W., 2014. The ameliorative effects of exogenous melatonin on grape cuttings under waterdeficient stress: antioxidant metabolites, leaf anatomy, and chloroplast morphology. J. Pineal Res. 57, 200212.

Nakano Y., Asada K., 1981. Hydrogen peroxide is scavenged by ascorbate specific peroxidase in spinach chloroplasts. Plant Cell Physiol. 22, 867-880.

Nawaz M.A., Huang Y., Bie Z., Ahmed W., Reiter R.J., Niu M., Hameed S., 2016. Melatonin: current status and future perspectives in plant science. Front Plant Sci. 6, 1230.

Polle A., 2001. Dissecting the superoxide dismutaseascorbate glutathione pathway in chloroplasts by metabolic modeling. Computer simulations as a step towards flux analysis. Plant Physiol. 126, 445-462.

Sarropoulou V., Therios I., Dimassi-Theriou K., 2012. Melatonin promotes adventitious root regeneration in in vitro shoot tip explants of the commercial sweet cherry rootstocks CAB-6P (Prunus cerasus L.), Gisela $6(P$. Cerasus $\times$ P. canescens $)$, and $\mathrm{M} \times \mathrm{M} 60($ P. avium $\times$ P. mahaleb). J. Pineal Res. 52, 38-46.

Sharma P., Dubey R.S., 2007. Involvement of oxidative stress and role of antioxidative defense system in growing rice seedlings exposed to toxic concentrations of aluminum. Plant Cell Rep. 26, 2027-2038.

Shi H., Chen K., Wei Y., He C., 2016. Fundamental issues of melatonin-mediated stress signaling in plants. Front. Plant Sci. 7, 1124.

Shi Q., Ding F., Wang X., Wei M., 2007. Exogenous nitric oxides protect cucumber roots against oxidative stress induced by salt stress. Plant Physiol. Biochem. 45, 542-550.

Tan D.X., Hardeland R., Manchester L.C., RosalesCorral S., Cotomontes A., Boga J.A., Reiter R.J., 2012. Emergence of naturally occurring melatonin isomers and their proposed nomenclature. J. Pineal Res. 53, 113-121.

Turk H., Erdal S., Genisel M., Atici O., Demir Y., YANMIS D., 2014. The regulatory effect of melatonin on physiological, biochemical and molecular parameters in cold-stressed wheat seedlings. Plant Growth Regul. 74, 139-152.

Velikova V., Yordanov I., Edreva A., 2000. Oxidative stress and some antioxidant systems in acid raintreated bean plants. Plant Sci. 151, 59-66.

Wang P., Sun X., Chang C., Feng F.J., Liang D., Cheng L.L., MA F.W., 2013b. Delay in leaf senescence of Malus hupehensis by long-term melatonin application is associated with its regulation of metabolic status and protein degradation. J. Pineal Res. 55, 424-434.

Wang P., Sun X., Li C., Wei Z.W., Liang D., Ma F.W., 2013a. Long-term exogenous application of melatonin delays drought-induced leaf senescence in apple. J. Pineal Res. 54, 292-302.

Wei W., Li Q.T., Chu Y.N., Reiter R.J., Yu X.M., Zhu D.H., Zhang W.K., Ma B., Lin Q., Zhang J.S., CHEN S.Y., 2015. Melatonin enhances plant growth and abiotic stress tolerance in soybean plants. J. Exp. Bot. 66, 695-707.

Wheutherley P.E., 1950. Studies in water relations of cotton plants. The field measurement of water deficit in leaves. New Phytol. 49, 81-87.

Wu G.Q., Zhang L.N., WANG Y.Y., 2012. Response of growth and antioxidant enzymes to osmotic stress in two different wheat (Triticum aestivum L.) cultivars seedlings. Plant Soil Environ. 58, 534-539.

Ye J., Wang S., Deng X., Yin L., Xiong B., Wang X., 2016. Melatonin increased maize (Zea mays L.) seedling drought tolerance by alleviating droughtinduced photosynthetic inhibition and oxidative damage. Acta Physiol. Plant. 38, 48.

Zhang H.J., Zhang N., Yang R.C., Wang L., Sun Q.Q., Li D.B., Cao Y.Y., Weeda S., Zhao B., Ren S., Guo Y.D., 2014. Melatonin promotes seed germination under high salinity by regulating antioxidant systems, ABA and GA4 interaction in cucumber (Cucumis sativus L.). J. Pineal Res. 57(3), 269-279.

Zhang N., Zhao B., Zhang H.J., Weeda S., Yang C., YANG Z.C., Ren S., Guo Y.D., 2013. Melatonin promotes water-stress tolerance, lateral root formation, and seed germination in cucumber (Cucumis sativus L.). J. Pineal Res. 54(1), 15-23.

Zhang Z., Pang X., Duan X., Ji Z.L., Jiang Y., 2005. Role of peroxidase in anthocyanine degradation in litchi fruit pericarp. Food Chem. 90(1-2), 47-52.

Zhao Y., Qi L.W., Wang W.M., ET Al., 2011. Melatonin improves the survival of cryopreserved callus of Rhodiola crenulata. J. Pineal Res. 50(1), 83-88.

Received October 9, 2017; accepted February 21, 2018 